\title{
Soret and hall effect on unsteady free convection flow past an infinite vertical plate with oscillatory suction velocity and variable permeability
}

\author{
Panneerselvi Rangasamy*, Nagarathinam Murugesan \\ Department of Mathematics, PSGR Krishnammal College for Women, Coimbatore 641004, India
}

Corresponding Author Email: panneerselvir@psgrkc.ac.in

https://doi.org/10.18280/ijht.360305

Received: 21 August 2017

Accepted: 2 August 2018

\section{Keywords:}

oscillatory suction velocity, uniform magnetic field, Eckert number, hall effect, Soret effect

\begin{abstract}
An unsteady, two dimensional, free convection flow with heat and mass transfer of a viscous, incompressible, electrically conducting fluid past an infinite vertical porous plate of time dependent permeability with oscillatory suction velocity and chemical reaction in the presence of Hall current effect and Soret effect is investigated. A uniform magnetic field is applied normal to the direction of flow. The dimensionless governing equations are solved using perturbation technique in Eckert number. Numerical evaluation of the analytical solutions is carried out for the velocity field, temperature distribution and concentration distribution. The results obtained are discussed for various emerging parameters such as Prandtl number (Pr), Grashof number (Gr), Modified Grashof number (Gm), Soret number (Sr), Schmidt number $(\mathrm{Sc})$, Sink strength parameter $(\mathrm{S})$, Eckert number $(\mathrm{Ec})$, and Hall parameter $(\mathrm{m})$ encountered in the problem under investigation.
\end{abstract}

\section{INTRODUCTION}

Combined buoyancy-generated heat and mass transfer due to temperature and concentration variations, in porous media, have several important applications in variety of engineering processes including heat exchanger devices, petroleum reservoirs, chemical catalytic reactors, solar energy porous wafer collector systems, ceramic materials, migration of moisture through air contained in fibrous insulations and grain storage installations and the dispersion of chemical contaminants through water-saturated soil, super convecting geothermic etc. The vertical free convection boundary layer flow in porous media owing to combined heat and mass transfer has been investigated by Bejan and Khair [3].

Lai and Kulacki [11] used the series expansion method to investigate coupled heat and mass transfer in natural convection from a sphere in a porous medium. Soundalgekar [17] analyzed the effects of variable suction and the horizontal magnetic field on the free convection flow past infinite vertical porous plate and made a comparative discussion of different parameters and the free convection flow of mercury and ionized air. Many works on heat and mass transfer have focused mainly on regular geometries, the recent studies of them such as heat and mass transfer along a vertical plate with variable surface temperature and concentration in the presence of the magnetic field studied by Elbashbeshy [5]. The structure of bonding interface and the composition of research varied with different temperatures is analyzed by Yang et al. [6].

Chamkha and Khaled [3] analysed similarity solutions for hydromagnetic simultaneous heat and mass transfer by natural convection from an inclined plate with internal heat generation or absorption. Soundalgekar [19] presented an exact solution to the flow of a viscous fluid. Jashim Uddin and Fazlul Hoque [8] investigated the convective flow of nanofluids inside an isosceles triangular shaped enclosure with the uneven bottom wall using nonhomogeneous dynamic model.
Moreover, study of heat and mass transfer flow in the presence of chemical reaction has received considerable attention due to its several practical applications in chemical and hydrometallurgical industries. Usually, chemical reactions are of two types, homogeneous and heterogeneous. A chemical reaction is said to be heterogeneous or homogenous depending on whether they occur at an interface or as a single phase volume reaction. A homogenous reaction occurs uniformly throughout the given phase, whereas a heterogeneous reaction takes place in a restricted region or within the boundary of a phase. Some of the numerous important applications of heat and mass transfer flow with chemical reaction can be found in catalytic chemical reactors, food processing, polymer production, manufacture of ceramics and glassware, smelting, undergoing exothermic or endothermic chemical reaction etc. Keeping in mind the significance of such study, several researchers investigated hydromagnetic free convection heat and mass transfer flow of a viscous, incompressible and electrically conducting fluid past a vertical plate in the presence of first order chemical reaction under different conditions. Some of the relevant research studies are due to Ibrahim et al. [7], Mohamed and Abo-Dahab [12], Singh and Kumar [16], Pal and Talukdar [14], Osman et al. [13] and Barik and Dash [2].

It was discovered in 1979 by Edwin Herbert Hall while working on his doctoral degree at the Johns Hopkins University in Baltimore, Maryland, USA. In fact, Hall current plays a key role in determining the flow features of the fluid flow problems because it induces secondary flow in the flowfield which is also the characteristics of Coriolis force. Therefore, it seems to be significant to compare and contrast the simultaneous effects of these two agencies on the fluid flow problems. Hall current finds applications in many scientific and engineering devices, viz. MHD power generators, Hall current accelerators, nuclear power reactors, magnetometers, underground energy storage system, Hall 
effect sensors, spacecraft propulsion etc. Taking into consideration the importance of combined effects of Hall current and rotation, Alam and Sattar [1] investigated unsteady hydromagnetic free convection heat and mass transfer flow with Hall effects in a rotating system in the presence of viscous dissipation and Joule heating. Recently, Seth et al. [15] studied effects of Hall current and rotation on unsteady hydromagnetic natural convection heat and mass transfer flow of an optically thick radiating fluid past an infinite vertical plate through porous medium.

It is to be noted that in all the above research studies, Soret (or thermo-diffusion) effect assumed to be neglected. But, Soret effect becomes significant when there exists a density difference in the flow regime i.e. in the areas such as hydrology, petrology and geo-sciences. This effect has various important applications in isotope separation, in mixture between gases with very light molecular weight $\left(\mathrm{H}_{2}, \mathrm{He}\right)$ and of medium molecular weight $\left(\mathrm{N}_{2}\right.$, air) etc. Looking into the importance of such effect, Jha and Singh [9] analyzed Soret effect on unsteady free convection and mass transfer flow past an impulsively started infinite vertical plate. Kafoussias [10] investigated Soret effect on unsteady hydromagnetic free convection heat and mass transfer past an infinite moving vertical plate for two cases of practical interest, namely, (i) impulsively started plate and (ii) uniformly accelerated plate. past an impulsively started infinite isothermal vertical plate with mass transfer.

The objective of the current work, is to analyze the heat and mass transfer effects on unsteady, two dimensional free convective flow of a viscous, incompressible electrically conducting fluid along a vertical plate with suction, embedded in a porous medium in the presence of uniform magnetic field by taking into account the effect of viscous dissipation, Soret and Hall effect. The equation of continuity, motion, energy and concentration which governs the flow field is solved by using the regular perturbation method. The behavior of velocity, temperature and concentration are discussed for variations in the governing parameters.

\section{MATHEMATICAL FORMULATION}

Consider an unsteady free convective, viscous, incompressible, electrically conducting fluid through porous medium past an infinite vertical porous plate with oscillatory suction velocity, variable permeability and heat absorbing sinks in the presence of hall current and Soret effect. Let the $\mathrm{x}$-axis be taken along the plate in the direction of the flow and $y$-axis normal to the plate.

A uniform magnetic field is introduced normal to the direction of flow. All the fluid properties are assumed to be constant except that of the influence of density variation with temperature and concentration. The basic flow medium is entirely due to the buoyancy force caused by temperature and concentration difference between the wall and the medium. The surface temperature and concentration level near the plate are raised uniformly.

Let $\bar{B}=\left(0, B_{0}, 0\right)$ and $\bar{V}=\left(u^{\prime}, v^{\prime}, 0\right)$. Under Boussenesq's approximation, the fundamental equations which governs the flow are

\section{Equation of continuity:}

$\frac{\partial V^{\prime}}{\partial y^{\prime}}=0$
That is

$V^{\prime}=-V_{0}^{\prime}\left(1+\varepsilon e^{i \omega^{\prime} t^{\prime}}\right)$

\section{Equation of momentum:}

$\frac{\partial u^{\prime}}{\partial t^{\prime}}+V^{\prime} \frac{\partial u^{\prime}}{\partial y^{\prime}}=g \beta\left(T^{\prime}-T_{\infty}^{\prime}\right)+g \beta^{\prime}\left(C^{\prime}-C_{\infty}^{\prime}\right)+\gamma \frac{\partial^{2} u^{\prime}}{\partial y^{\prime 2}}-$

$\frac{\sigma B_{0}^{2}}{P\left(1+m^{2}\right)} u^{\prime}-\frac{\gamma}{K^{\prime}} u^{\prime}$

\section{Equation of Energy:}

$\frac{\partial T^{\prime}}{\partial t^{\prime}}+V^{\prime} \frac{\partial T^{\prime}}{\partial y^{\prime}}=\frac{K}{\rho C_{p}} \frac{\partial^{2} T^{\prime}}{\partial y^{\prime 2}}+S^{\prime}\left(T^{\prime}-T_{\infty}^{\prime}\right)+\frac{\gamma}{C_{p}}\left(\frac{\partial u^{\prime}}{\partial y^{\prime}}\right)^{2}$

On disregarding the Joule's heating

\section{Equation of Concentration:}

$\frac{\partial C^{\prime}}{\partial t^{\prime}}+V^{\prime} \frac{\partial C^{\prime}}{\partial y^{\prime}}=D \frac{\partial^{2} C^{\prime}}{\partial y^{\prime 2}}+K_{1}\left(C^{\prime}-C_{\infty}^{\prime}\right)+D_{m}\left(\frac{\partial^{2} T^{\prime}}{\partial y^{\prime 2}}\right)$

The corresponding boundary conditions are given by

$\mathrm{U}^{\prime}=0, V^{\prime}=-V_{0}^{\prime}\left(1+\varepsilon e^{i \omega^{\prime} t^{\prime}}\right)$

,$T^{\prime}=T_{w}^{\prime}+\varepsilon\left(T_{w}^{\prime}-T_{\infty}^{\prime}\right) e^{i \omega^{\prime} t^{\prime}}$

$C^{\prime}=C_{w}^{\prime}+\varepsilon\left(C_{w}^{\prime}-C_{\infty}^{\prime}\right) e^{i \omega^{\prime} t^{\prime}}$

$u^{\prime} \rightarrow 0, T^{\prime} \rightarrow T_{w}^{\prime}, C^{\prime} \rightarrow C_{w}^{\prime}$

at $y^{\prime}=0$

as $\mathrm{y}^{\prime} \rightarrow \infty$

Introduce the non dimensional parameters

$y=\frac{y^{\prime} V_{0}^{\prime}}{v} ; t=\frac{t^{\prime} V_{0}^{\prime 2}}{4 v} ; \omega=\frac{4 v \omega^{\prime}}{V_{0}^{\prime 2}} ; u=\frac{u^{\prime}}{V_{0}^{\prime}} ; v=\frac{\mu}{\rho} ; \quad V=\frac{V^{\prime}}{V_{0}^{\prime}} ;$

$T=\left(\frac{T^{\prime}-T \infty^{\prime}}{T w^{\prime}-T \infty^{\prime}}\right) \quad C=\left(\frac{C^{\prime}-C \infty^{\prime}}{C w^{\prime}-C \infty^{\prime}}\right)$

Substitute the non dimensional parameters into (2) - (5) it reduces to

$$
\begin{aligned}
& \frac{1}{4} \frac{\partial u}{\partial t}-\frac{\partial u}{\partial y}\left(1+\varepsilon e^{i \omega t}\right)=G r T+\mathrm{GmC}+\frac{\partial^{2} \mathrm{u}}{\partial \mathrm{y}^{2}}-M_{1} u- \\
& \frac{u}{K_{0}\left(1+\varepsilon e^{i \omega t}\right)} \\
& \frac{\operatorname{Pr}}{4} \frac{\partial T}{\partial t}-\left(1+\varepsilon e^{i \omega t}\right) \frac{\partial T}{\partial y}=\frac{\partial^{2} \mathrm{~T}}{\partial \mathrm{y}^{2}}+\frac{\operatorname{Pr}}{4} S T+\operatorname{PrEC}\left(\frac{\partial u}{\partial y}\right)^{2}
\end{aligned}
$$

where $M_{1}=\frac{M}{1+m^{2}}$

$\frac{1}{4} \frac{\partial c}{\partial t}-\left(1+\varepsilon e^{i \omega t}\right) \frac{\partial c}{\partial y}=\frac{1}{S C} \frac{\partial^{2} c}{\partial y^{2}}+K_{2} C+S r \frac{\partial^{2} T}{\partial y^{2}}$

The non dimensionalized boundary conditions are

$$
\mathrm{u}=0, \mathrm{~T}=1+\varepsilon e^{i \omega t}, \mathrm{C}=1+\varepsilon e^{i \omega t} \text { at } \mathrm{y}=0 \text { and }
$$$$
\mathrm{u} \rightarrow 0, \mathrm{~T} \rightarrow 0, \mathrm{C} \rightarrow 0 \text { as } \mathrm{y} \rightarrow \infty
$$

To solve equation (8), (9) and (10), we assume from V.M. Soundalgekar, J.P Bhat [19] that

$$
\begin{aligned}
& \mathrm{u}(\mathrm{y}, \mathrm{t})=\mathrm{u}_{0}(\mathrm{y})+\varepsilon e^{i \omega t} \mathrm{u}_{1}(\mathrm{y}) \\
& \mathrm{T}(\mathrm{y}, \mathrm{t})=\mathrm{T}_{0}(\mathrm{y})+\varepsilon e^{i \omega t} \mathrm{~T}_{1}(\mathrm{y})
\end{aligned}
$$


$\mathrm{C}(\mathrm{y}, \mathrm{t})=\mathrm{C}_{0}(\mathrm{y})+\varepsilon e^{i \omega t} \mathrm{C}_{1}(\mathrm{y})$

Substituting (12) - (14) in equation (8) - (10), equating like terms and neglecting the co-efficient of higher powers of $\varepsilon$, we get

$\frac{\partial^{2} u_{0}}{\partial y^{2}}+\frac{\partial u_{0}}{\partial y}-A_{1} u_{0}=-G r T_{0}-G m C_{0}$

$\frac{\partial^{2} u_{1}}{\partial y^{2}}+\frac{\partial u_{1}}{\partial y}-A_{2} u_{1}=-G r T_{1}-G m C_{1} \frac{\partial u_{0}^{\prime}}{\partial y}-\frac{1}{K_{0}} u_{0}$

$\frac{\partial^{2} T_{0}}{\partial y^{2}}+\operatorname{Pr} \frac{\partial T_{0}}{\partial y}+\frac{\operatorname{PrS}}{4} T_{0}=-\operatorname{PrEc}\left(\frac{\partial u_{0}}{\partial y}\right)^{2}$

$\frac{\partial^{2} T_{1}}{\partial y^{2}}+\operatorname{Pr} \frac{\partial T_{1}}{\partial y}+\frac{P r}{4}[S-i \omega] T_{1}=-2 \operatorname{PrEc} \frac{\partial u_{0}}{\partial y} \frac{\partial u_{1}}{\partial y}-\operatorname{Pr} \frac{\partial T_{0}}{\partial y}$

$\frac{\partial^{2} C_{0}}{\partial y^{2}}+S c \frac{\partial C_{0}}{\partial y}+S c K_{2} C_{0}=-S c S r T_{0}^{\prime \prime}$

$\frac{\partial^{2} C_{1}}{\partial y^{2}}+S c \frac{\partial C_{1}}{\partial y}+S c K_{1} C_{1}=-S c \frac{\partial C_{0}}{\partial y}-S r S c \frac{\partial^{2} T_{1}}{\partial y^{2}}$

The associated boundary conditions will become as

$\mathrm{u}_{0}=0, \mathrm{u}_{1}=0, \mathrm{~T}_{0}=1, \mathrm{~T}_{1}=0, \mathrm{C}_{0}=1, \mathrm{C}_{1}=0$ at $\mathrm{y}=0$

$\mathrm{u}_{0} \rightarrow 0, \mathrm{u}_{0} \rightarrow 0, \mathrm{~T}_{0} \rightarrow 0, \mathrm{~T}_{1} \rightarrow 0, \mathrm{C}_{0} \rightarrow 0, \mathrm{C}_{1} \rightarrow 0$ as $\mathrm{y} \rightarrow \infty$

Using multi parameter perturbation technique and assuming Ec $<<1$, we write

$\mathrm{u}_{0}=\mathrm{u}_{00}+\mathrm{Ecu}_{01}: \mathrm{T}_{0}=\mathrm{T}_{00}+\mathrm{Ec} \mathrm{T}_{01}: \mathrm{C}_{0}=\mathrm{C}_{00}+\mathrm{Ec} \mathrm{C}_{01}$

$\mathrm{u}_{1}=\mathrm{u}_{10}+\mathrm{Ecu}_{11}: \mathrm{T}_{1}=\mathrm{T}_{10}+\mathrm{Ec} \mathrm{T}_{11}: \quad \mathrm{C}_{1}=\mathrm{C}_{10}+\mathrm{Ec} \mathrm{C}_{11}$

Using Equation (22) \& (23) in the equation (15) - (20) and equating the co-efficient of $\mathrm{Ec}^{\circ}$ and $\mathrm{Ec}^{1}$ only, we get the following sets of differential equations for $\mathbf{u}_{00}, \mathbf{u}_{01}, \mathbf{u}_{10}, \mathbf{u}_{11}$, and $\mathrm{T}_{00}, \mathrm{~T}_{01}, \mathrm{~T}_{10}, \mathrm{~T}_{11}$ and $\mathrm{C}_{00}, \mathrm{C}_{01}, \mathrm{C}_{10}, \mathrm{C}_{11}$

$u_{00}^{\prime \prime}+u_{0}^{\prime}-A_{1} u_{00}=-G r T_{00}-G m C_{00}$

$u_{01}^{\prime \prime}+u_{01}^{\prime}-A_{1} u_{01}=-G r T_{01}-G m C_{01}$

$u_{10}^{\prime \prime}+u_{10}^{\prime}-A_{2} u_{10}=-G r T_{10}-G m C_{10}-u_{00}^{\prime}-\frac{1}{k_{0}} u_{00}$

$u_{11}^{\prime \prime}+u_{11}^{\prime}-A_{2} u_{11}=-G r T_{11}-G m C_{11}-u_{01}^{\prime}-\frac{1}{k_{0}} u_{01}$

$T_{00}^{\prime \prime}+\operatorname{Pr} T_{00}^{\prime}+\frac{P r S}{4} T_{00}=0$

$T_{01}^{\prime \prime}+\operatorname{Pr} T_{01}^{\prime}+\frac{P r S}{4} T_{01}=-\operatorname{Pr}\left(u_{00}^{\prime}\right)^{2}$

$T_{10}^{\prime \prime}+\operatorname{Pr} T_{10}^{\prime}+\frac{P r}{4}(i w-s) T_{10}=-P r T_{00}^{\prime}$

$T_{11}^{\prime \prime}+\operatorname{Pr} T_{11}^{\prime}-\frac{P r}{4}(i w-s) T_{11}=-2 \operatorname{Pr} u_{00}^{\prime} u_{10}^{\prime}-$ $\operatorname{PrT}_{01}^{\prime}(31)$

$C_{00}^{\prime \prime}+S c C_{00}^{\prime}+S c K_{2} C_{00}=-S c S r T_{00}^{\prime \prime}$

$C_{01}^{\prime \prime}+S c C_{01}^{\prime}+S c K_{2} C_{01}=-S c S r T_{01}^{\prime \prime}$
$C_{10}^{\prime \prime}+S c C_{10}^{\prime}+S c K_{1} C_{10}=-S c C_{00}^{\prime}-S c S r T_{10}^{\prime \prime}$

$C_{11}^{\prime \prime}+S c C_{11}^{\prime}+S c K_{1} C_{11}=-S c C_{01}^{\prime}-S c S r T_{11}^{\prime \prime}$

and the corresponding boundary conditions are

$\mathrm{u}_{00}=0, \mathrm{u}_{01}=0, \quad \mathrm{~T}_{00}=1, \mathrm{~T}_{01}=0, \mathrm{C}_{00}=1, \mathrm{C}_{01}=0$

$\mathrm{u}_{10}=0, \mathrm{u}_{11}=0, \mathrm{~T}_{10}=1, \mathrm{~T}_{11}=0, \mathrm{C}_{10}=1, \mathrm{C}_{11}=0 \quad$ at $\mathrm{y}=0$

$\mathrm{u}_{00} \rightarrow 0, \mathrm{u}_{01} \rightarrow 0, \mathrm{~T}_{00} \rightarrow 0, \mathrm{~T}_{01} \rightarrow 0, \mathrm{C}_{00} \rightarrow 0, \mathrm{C}_{01} \rightarrow 0$

$\mathrm{u}_{01} \rightarrow 0, \mathrm{u}_{11} \rightarrow 0, \mathrm{~T}_{01} \rightarrow 0, \mathrm{~T}_{11} \rightarrow 0, \mathrm{C}_{01} \rightarrow 0, \mathrm{C}_{11} \rightarrow 0$ as $\mathrm{y} \rightarrow \infty$

Solving these differential equation (24) - (35) with the help of the corresponding boundary conditions and then substitute the values in the relations (22) and (23), we obtain the mean velocity, mean temperature and mean concentration as,

$$
\begin{aligned}
u_{0}= & \left(\left(A_{3}+A_{4}\right) e^{-a_{8} y}-A_{3} e^{-a_{2} y}-A_{4} e^{-a_{6} y}\right) \\
& +E c\left(D_{36} e^{-a_{8} y}-D_{28} e^{-a_{2} y}-D_{29} e^{-a_{6} y}+D_{30} e^{-2 a_{8} y}\right. \\
& +D_{31} e^{-2 a_{2} y}+D_{32} e^{-2 a_{6} y}-D_{33} e^{-\left(a_{2}+a_{8}\right) y} \\
& \left.+D_{34} e^{-\left(a_{2}+a_{6}\right) y}-D_{35} e^{-\left(a_{6}+a_{8}\right) y}\right) \\
u_{1}= & \left(D_{19} e^{-a_{10} y}-D_{14} e^{-a_{4} y}-D_{15} e^{-a_{2} y}-D_{16} e^{-a_{12} y}\right. \\
& \left.-D_{17} e^{-a_{8} y}-D_{18} e^{-a_{6} y}\right)+E c\left(D_{93} e^{-a_{10} y}\right. \\
& +D_{73} e^{-a_{4} y}+D_{74} e^{-\left(a_{8}+a_{10}\right) y}+D_{75} e^{-\left(a_{4}+a_{8}\right) y} \\
& +D_{76} e^{-\left(a_{2}+a_{8}\right) y}+D_{77} e^{-\left(a_{8}+a_{12}\right) y}+D_{78} e^{-2 a_{8} y} \\
& +D_{79} e^{-\left(a_{61}+a_{8}\right) y}+D_{80} e^{-\left(a_{2+}+a_{10}\right) y}+D_{81} e^{-\left(a_{2}+a_{4}\right) y} \\
& +D_{82} e^{-2 a_{2} y}+D_{83} e^{-2 a_{6} y}+D_{84} e^{-\left(a_{2}+a_{12}\right) y} \\
& +D_{85} e^{-\left(a_{2}+a_{6}\right) y}+D_{86} e^{-\left(a_{6}+a_{10}\right) y} \\
& +D_{87} e^{-\left(a_{4}+a_{6}\right) y}+D_{88} e^{-\left(a_{6}+a_{12}\right) y}+D_{89} e^{-a_{2} y} \\
& +D_{90} e^{-a_{12} y}+D_{91} e^{-a_{61} y}+D_{92} e^{\left.-a_{8} y\right)} \\
& \left(e^{-a_{2} y}\right)+E c\left(D_{9} e^{-a_{2} y}-D_{3} e^{-2 a_{8} y}\right. \\
& -D_{4} e^{-2 a_{2} y}-D_{5} e^{-2 a_{6} y}+D_{6} e^{-\left(a_{2}+a_{8}\right) y} \\
& \left.-D_{7} e^{-\left(a_{2}+a_{6}\right) y}+D_{8} e^{-\left(a_{6}+a_{8}\right) y}\right)
\end{aligned}
$$

$$
\begin{aligned}
T_{1}= & \left(\left(1-D_{1}\right) e^{-a_{4} y}+D_{1} e^{-a_{2} y}\right)+E c\left(D_{53} e^{-a_{4} y}\right. \\
& +D_{37} e^{-\left(a_{8}+a_{10}\right) y}+D_{38} e^{-\left(a_{4}+a_{8}\right) y}+D_{39} e^{-\left(a_{2}+a_{8}\right) y} \\
& +D_{40} e^{-\left(a_{8}+a_{12}\right) y}+D_{41} e^{-2 a_{8} y}+D_{42} e^{-\left(a_{6+} a_{8}\right) y} \\
& +D_{43} e^{-\left(a_{2+} a_{10}\right) y}+D_{44} e^{-\left(a_{2+} a_{4}\right) y}+D_{45} e^{-2 a_{2} y} \\
& +D_{46} e^{-2 a_{6} y}+D_{47} e^{-\left(a_{2+} a_{12}\right) y}+D_{48} e^{-\left(a_{2+} a_{6}\right) y} \\
& +D_{49} e^{-\left(a_{6+} a_{10}\right) y}+D_{50} e^{-\left(a_{4+} a_{6}\right)} \\
& \left.+D_{51} e^{-\left(a_{6+} a_{12}\right) y}+D_{52} e^{-a_{2} y}\right)
\end{aligned}
$$

$$
\begin{aligned}
C_{0}= & \left(\left(1-D_{2}\right) e^{-a_{6} y}+D_{2} e^{-a_{2} y}\right)+E c\left(D_{27} e^{-a_{6} y}\right. \\
& +D_{20} e^{-a_{2} y}-D_{21} e^{-2 a_{\mathrm{B}} y}-D_{22} e^{-2 a_{2} y} \\
& -D_{23} e^{-2 a_{6} y}+D_{24} e^{-\left(a_{2}+a_{8}\right) y} \\
& \left.-D_{25} e^{-\left(a_{2}+a_{6}\right) y}+D_{26} e^{-\left(a_{6}+a_{8}\right) y}\right)
\end{aligned}
$$

$$
\begin{aligned}
C_{1}= & \left(D_{13} e^{-a_{12} y}+D_{10} e^{-a_{6} y}-D_{11} e^{-a_{2} y}\right. \\
& \left.+D_{12} e^{-a_{4} y}\right)+\operatorname{Ec}\left(D_{72} e^{-a_{12} y}+D_{54} e^{-a_{66} y}\right. \\
& +D_{55} e^{-a_{2} y}+D_{56} e^{-a_{4} y}+D_{57} e^{-2 a_{8} y} \\
& +D_{58} e^{-2 a_{2} y}+D_{59} e^{-2 a_{61} y} \\
& +D_{60} e^{-\left(a_{2}+a_{8}\right) y}+D_{61} e^{-\left(a_{2}+a_{6}\right) y} \\
& +D_{62} e^{-\left(a_{6}+a_{8}\right) y}+D_{63} e^{-\left(a_{8}+a_{10}\right) y} \\
& +D_{64} e^{-\left(a_{4}+a_{8}\right) y}+D_{65} e^{-\left(a_{8}+a_{12}\right) y} \\
& +D_{66} e^{-\left(a_{2}+a_{10}\right) y}+D_{67} e^{-\left(a_{2}+a_{4}\right) y} \\
& +D_{68} e^{-\left(a_{2}+a_{12}\right) y}+D_{69} e^{-\left(a_{6}+a_{10}\right) y} \\
& \left.+D_{70} e^{-\left(a_{4}+a_{6}\right)}+D_{71} e^{-\left(a_{6}+a_{12}\right) y}\right)
\end{aligned}
$$


where the constants $\mathrm{a}_{2}, \mathrm{a}_{4}, \mathrm{a}_{6}, \mathrm{a}_{8}, \mathrm{a}_{10}, \mathrm{D} 1, \mathrm{D}_{2}, \mathrm{D}_{3}, \mathrm{D}_{4}, \ldots$ used above are function of the physical parameters involved in the problem given in Appendix.

\section{SKIN FRICTION, RATE HEAT AND MASS TRANSFER}

Skin friction co-efficient $(\tau)$ at the plate is

$\tau=\left(\frac{\partial c}{\partial y}\right)_{y=0}=u_{0}^{\prime}(0)+\varepsilon e^{i \omega t} u_{1}^{\prime}(0)$

Heat transfer coefficient $(\mathrm{Nu})$ at the plate is

$N_{u}=-\left(\frac{\partial T}{\partial y}\right)_{y=0}=T_{0}^{\prime}(0)+\varepsilon e^{i \omega t} T_{1}^{\prime}(0)$

Mass transfer coefficient $\left(\mathrm{S}_{\mathrm{h}}\right)$ at the plate is

$S_{h}=-\left(\frac{\partial C}{\partial y}\right)_{y=0}=C_{0}^{\prime}(0)+\varepsilon e^{i \omega t} C_{1}^{\prime}(0)$

\section{RESULT AND DISCUSSION}

The formulation of the problem that accounts for the viscous dissipation effect on the flow of a viscous incompressible fluid along a vertical infinite plate embedded in a porous medium in the presence of uniform magnetic field with Hall and Soret effect is accomplished. The governing equations of the flow field were solved analytically, using a perturbation method, and the expressions for the velocity, temperature, concentration were obtained. In order to get a physical insight of the problem, the above physical quantities are computed numerically for different values of the governing parameters viz. the thermal Grashof number $(G r)$, the solutal Grashof number $(G c)$, the Prandtl number $(P r)$, the Schmidt number $(S c)$, the Eckert number $(\mathrm{E})$, the Hall parameter $(\mathrm{m})$ and the Porosity parameter $\left(\mathrm{K}_{0}\right) .(\mathrm{Pr}=0.71, \mathrm{Ec}=0.001, \mathrm{Sc}=$ $0.22, \mathrm{~K}_{2}=1.0, \mathrm{~K}_{1}=1.0, \mathrm{~K}_{0}=10, \mathrm{M}=2.0, \varepsilon=0.1, \omega \mathrm{t}=\pi / 2, \mathrm{Gr}$ $=5.0, \mathrm{Sr}=1.0, \mathrm{Gm}=2.0, \mathrm{~S}=1, \mathrm{~m}=1.0$ ).

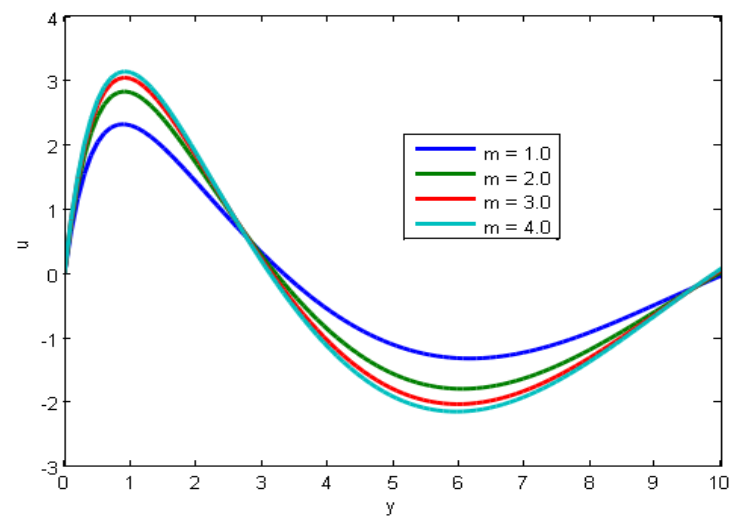

Figure 1. Velocity profile for various $\mathrm{m}$

Fig. 1 shows the velocity profiles in the boundary layer for various values of $\mathrm{m}$. Fig.1 illustrates the influence of Hall parameter on the velocity $u$ for the case of air $(\operatorname{Pr}=0.7)$. It is observed that the velocity increases rapidly near to the wall of the porous plate, reaches a maximum and decays then shows the reverse behavior for various $m$. This is because of the fact that the application of the transverse magnetic field to an electrically conducting fluids gives rise to a respective type of force known as Lorentz force. This force has the tendency to slowdown the motion of the fluid in the boundary layer.

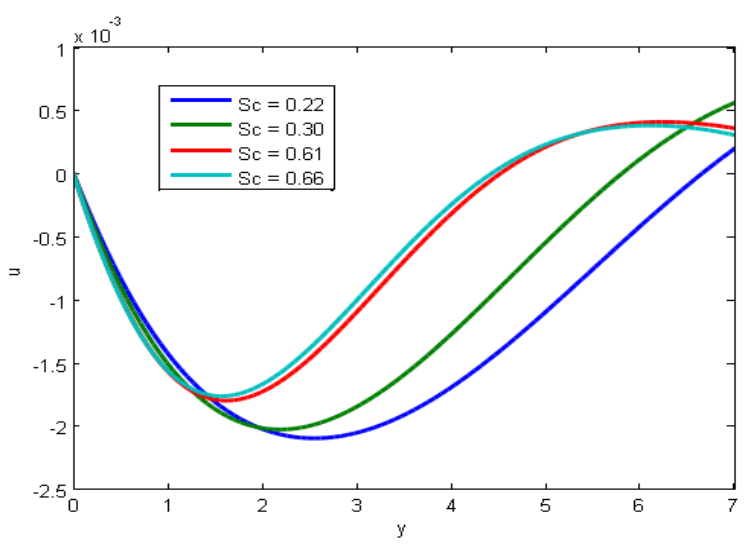

Figure 2. Velocity profile for various Sc

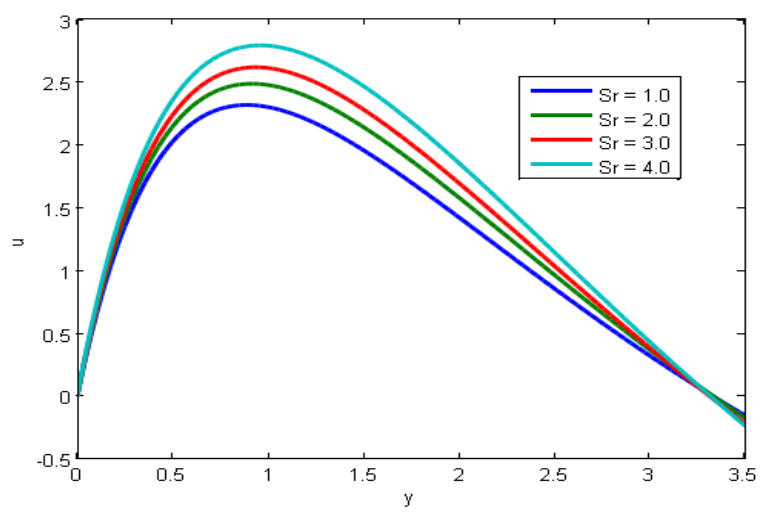

Figure 3. Velocity profile for various $\mathrm{Sr}$

Fig. 2 presents the typical velocity profiles in the boundary layer for various values of the Schmidt number (Sc). The velocity distribution decreases ant then showing the increasing profile when Sc increases. Fig.3 exhibits the typical velocity profiles in the boundary layer for various values of the Soret number $(\mathrm{Sr})$. The velocity distribution attains a distinct maximum value in the vicinity of the plate and then decreases properly to approach a free stream value of $y$.

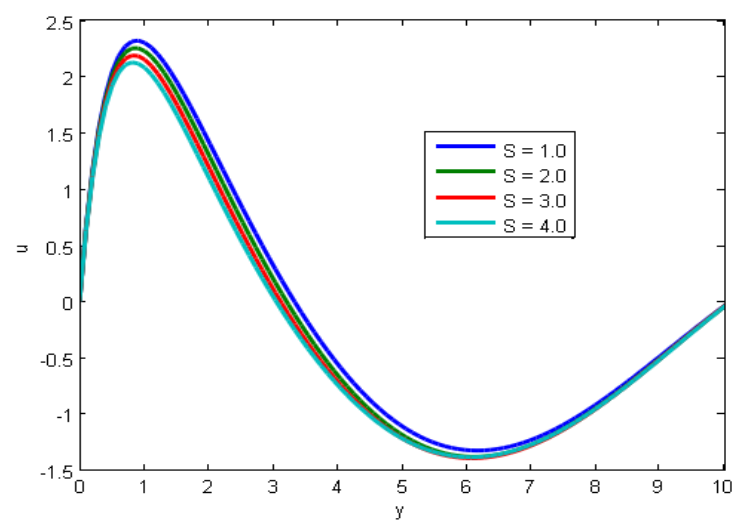

Figure 4. Velocity profile for various $S$

Fig. 4 represents the velocity profile for various values of S. As expected, velocity increases with the increase in heat 
source parameter. For the case of different values of the thermal Grashof number, the velocity profiles in boundary layer are shown in fig. 5 for air $(\operatorname{Pr}=0.71)$ and water $(\mathrm{Pr}=$ 7.1). It is observed that an increase in $G r$ leads to a rise in the values of velocity due to enhancement in buoyancy force.

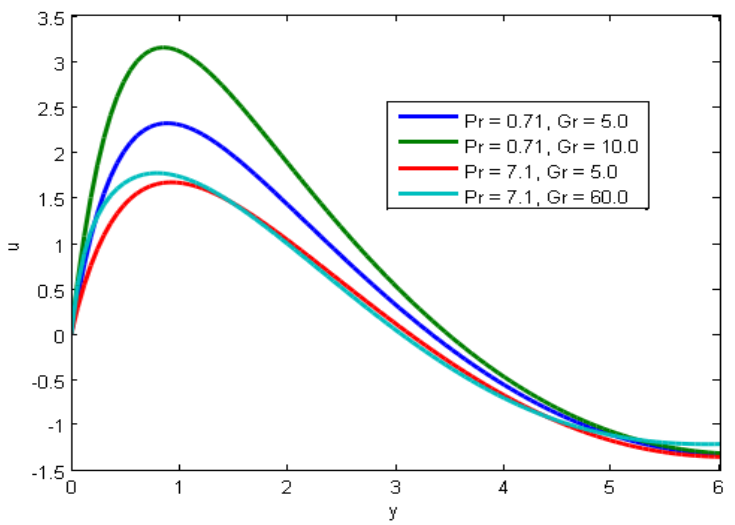

Figure 5. Velocity profile for various $\mathrm{Gr}$

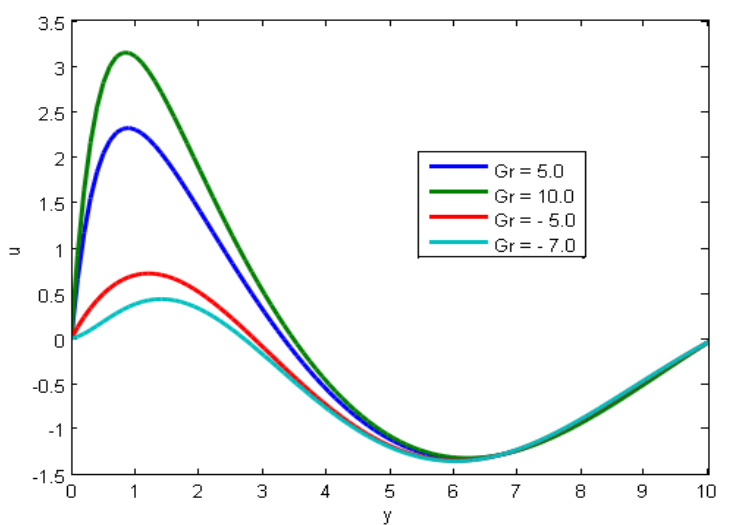

Figure 6. Velocity profile for various $\mathrm{Gr}>0$ and $\mathrm{Gr}<0$

The effects of thermal Grashof number on the velocity are shown in Fig. 6. When $\mathrm{Gr}>0$ the velocity increases rapidly and decreases when $\mathrm{Gr}<0$. Here, the positive values of $\mathrm{Gr}$ correspond to heating of the plate and negative values of $\mathrm{Gr}$ correspond to cooling of the plate. In addition, it is observed that the velocity increases sharply near the wall of the porous plate as $\mathrm{Gr}$ increases and then decays to the free stream value. Fig. 7, shows velocity profiles for different values of the porosity parameter $\mathrm{K}_{0}$. It is observed that the fluid velocity increases sharply, attains a peak value near to the plate and decays continuously till $\mathrm{y}=3.0$ and then the velocity decreases.

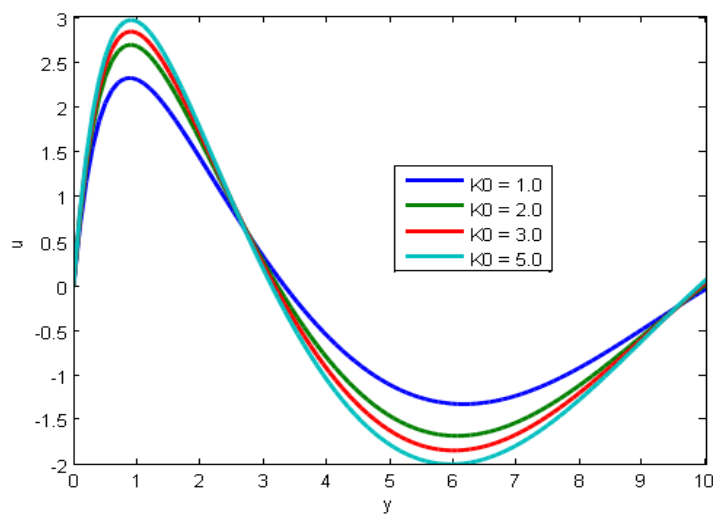

Figure 7. Velocity profile for various $\mathrm{K}_{0}$
For the case of different values of the solutal Grashof number, the velocity profiles in boundary layer are shown in Fig. 8. As expected, the fluid velocity increases and the peak value becomes more distinctive due to increase in the buoyancy force represented by $G c$. The effects of the viscous dissipation parameter i.e. the Eckert number on temperature is shown in Fig. 9. It is observed that the temperature increases near the plate, then decays continuously with increasing $y$.

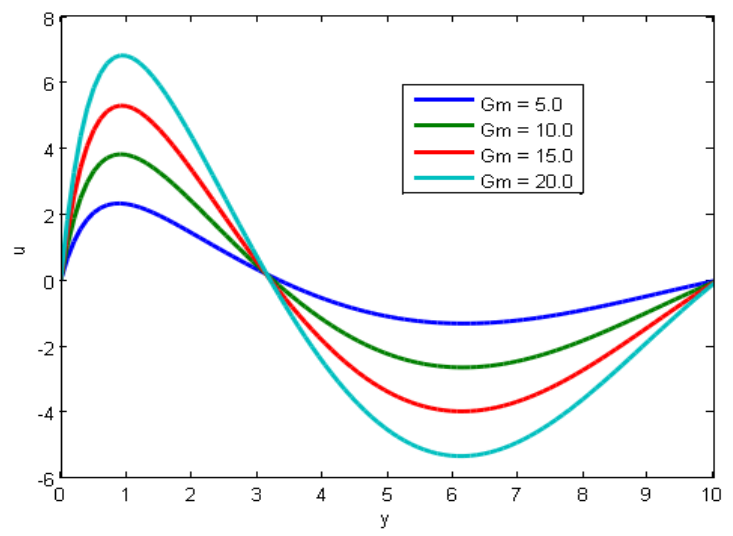

Figure 8. Velocity profile for various $\mathrm{Gm}$

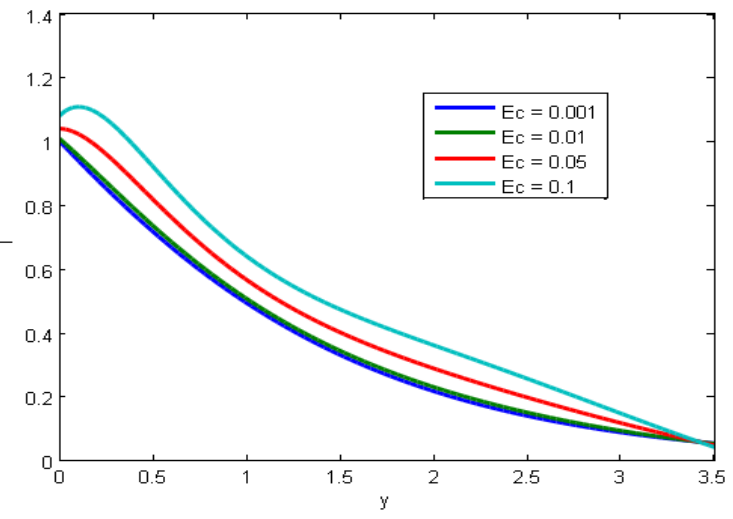

Figure 9. Temperature profile for various Ec

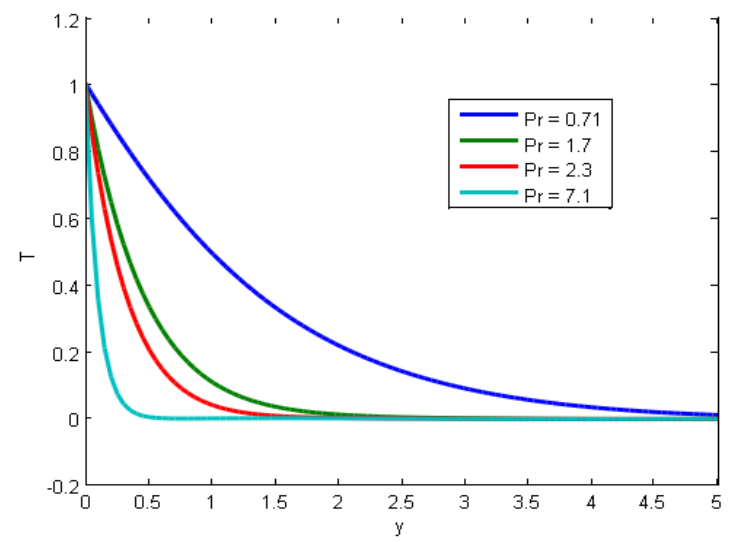

Figure 10. Temperature profile for various $\operatorname{Pr}$

Fig. 10. shows the behavior of temperature for different values of Prandtl number. It is observed that an increase in the Prandtl number results a decrease of the thermal boundary layer thickness. The reason is that smaller values of $P r$ are equivalent to increase in the thermal conductivity of the fluid and therefore, heat is able to diffuse away from the heated surface more rapidly for higher values of $\mathrm{Pr}$. Fig. 11 depicts the effect of sink strength parameter $S$ on the temperature profiles of the flow field. Curve with $S>0$ represent the presence of heat sink in the flow field. From figure, it is seen 
that a growing sink strength parameter decreases the temperature of the flow field.

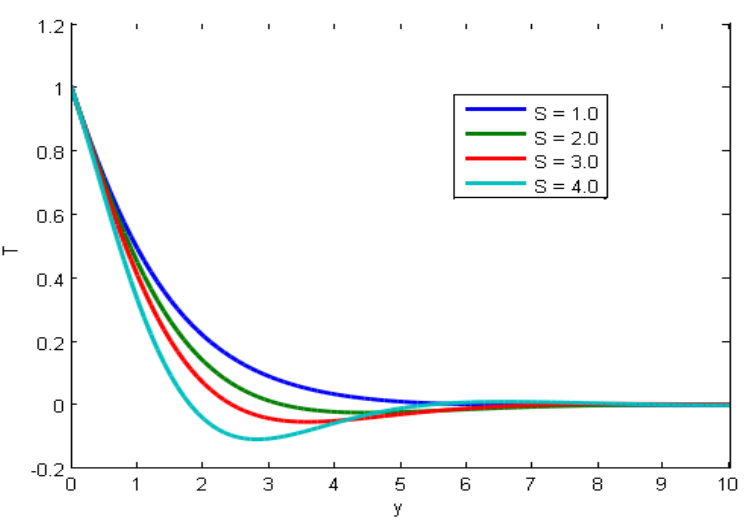

Figure 11. Temperature profile for various $S$

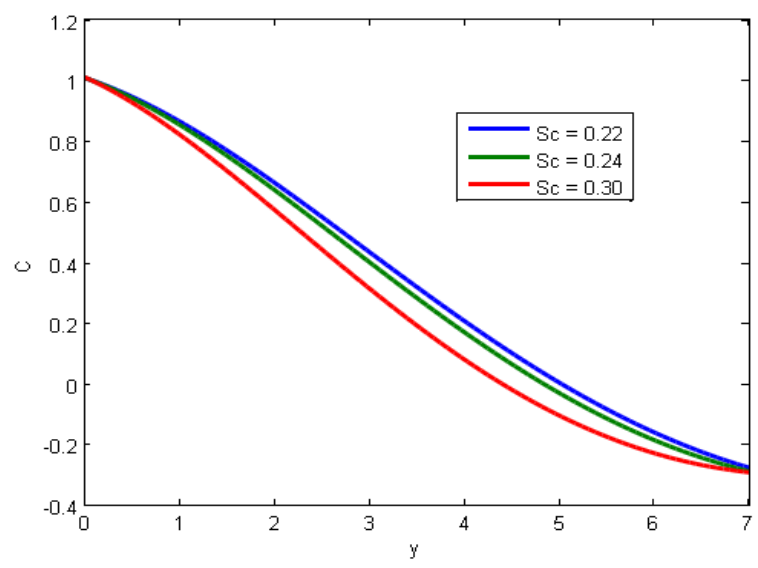

Figure 12. Concentration profile for various Sc

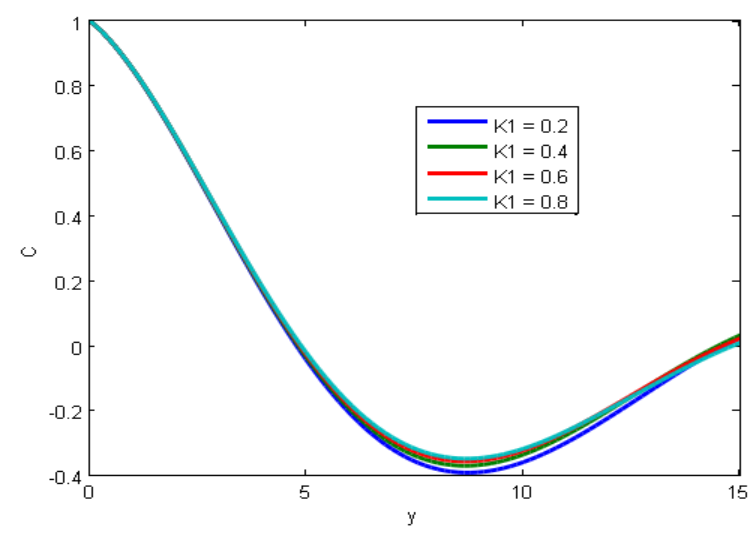

Figure 13. Concentration profile for various $\mathrm{K}_{1}$

Figs 12 and 13. Depicts the concentration profile for various $\mathrm{Sc}$ and $\mathrm{K}_{1}$. From Fig. 12 it is perceived that, species concentration decreases as the Schmidt number increases. From Fig 13, it is noticed that the concentration increases with the increase in chemical reaction parameter.

\section{CONCLUSION}

The governing equations for unsteady, incompressible MHD free convective heat and mass transfer flow past an infinite vertical plate embedded in a porous medium with Hall and Soret effect was formulated. Viscous dissipation effects were also included in the present work. The plate velocity is maintained at constant value and the flow was subjected to a transverse magnetic field. The resulting partial differential equations were transformed into a set of ordinary differential equations using two- term series and solved in closed form. Numerical evaluations of the closed form results were performed and graphical results were obtained to illustrate the details of the flow, heat and mass transfer characteristics and their dependence on some physical parameters. It was found that velocity increases rapidly near the wall and then decreases to free stream as Hall parameter, Schmidt number, Porosity parameter and Soret number increases. The velocity profile decreases with the increase in sink strength parameter. It was also found that when thermal and solutal Grashof numbers were increased, the thermal and concentration buoyancy effects were enhanced and thus, the fluid velocity increased. The temperature profile increases with the increase in Eckert number and decreases with the increase in Prandtl number and Sink strength parameter. Also, when the Schmidt number was increased, the concentration level gets decreased resulting in decreased fluid velocity. In addition, it is found that concentration profile increases with the increase in chemical reaction parameter.

\section{REFERENCES}

[1] Alam MM, Sattar MA. (2000). Unsteady MHD free convection and mass transfer flow in a rotating system with Hall current, viscous dissipation and Joule heating. J. Energy Heat Mass Transf. 22: 31-39.

[2] Barik RN, Dash GC, Kar M. (2014). Unsteady free convective MHD flow and mass transfer through porous medium in a rotating system with fluctuating heat source/sink and chemical reaction. J. Appl. Analys. Comput. 4(3): 231-244.

[3] Bejan A, Khair KR. (1985). Mass transfer to natural convection boundary layer flow driven by heat transfer. Journal of Heat Transfer 107(4): 979-981.

[4] Chamkha AJ, Khaled ARA. (2001). Similarity solutions for hydro magnetic simultaneous Heat and Mass Transfer by natural convection from an inclined plate with heat generation or absorption. Heat Mass Transfer 37: 117123.

[5] Elbashbeshy EMA. (1997). Heat and mass transfer along a vertical plate with variable surface tension and concentration in the presence of magnetic field. International Journal of Engineering Science 34(5): 515522.

[6] Yang GM, Ma DL, Liu L, Rong J, Yu XH. (2017). Thermal diffusion bonding of pure titanium to 304 stainless steel using aluminum interlayer. Chemical Engineering Transactions 59. https://doi.org/10.3303/CET1759175

[7] Ibrahim FS, Elaiw AM, Bakr AA. (2008). Effect of the chemical reaction and radiation absorption on the unsteady MHD free convection flow past a semi infinite vertical permeable moving plate with heat source and suction. Comm. Nonlinear Sci. Numer. Simulat. 13(6): 1056-1066.

[8] Jashim Uddin Md, Fazlul Hoque AKM. (2018). Convective heat transfer flow of nanofluid in an isosceles triangular shaped enclosure with an uneven bottom wall. Chemical Engineering Transactions 66: 403-408. https://doi.org/10.3303/CET1866068

[9] Jha BK, Singh AK. (1970). Soret effects on freeconvection and mass transfer flow in the Stokes problem 
for an infinite vertical plate. Astrophys. Space Sci. 173(2): 251-255.

[10] Kafoussias NG. (1992). MHD thermal-diffusion effects on free-convective and mass-transfer flow over an infinite vertical moving plate. Astrophys. Space Sci. 192(1): 11-19

[11] Lai FC, Kulachi FA. (1990). The effects of variable viscosity on convective heat transfer along a vertical surface in a saturated porous medium. Int. J. Heat and Mass Transfer 33: 1028-1031.

[12] Mohamed RA, Abo-Dahab SM. (2009). Influence of chemical reaction and thermal radiation on the heat and mass transfer in MHD micropolar flow over a vertical moving porous plate in a porous medium with heat generation. Int. J. Thermal Sci. 48(9): 1800-1813.

[13] Osman ANA, Abo-Dahab SM, Mohamed RA. (2011). Analytical solution of thermal radiation and chemical reaction effects on unsteady MHD convection through porous media with heat source/sink. Math Prob. Eng. 118. https://doi.org/10.1155/2011/205181

[14] Pal D, Talukdar B. (2011). Combined effects of Joule heating and chemical reaction on unsteady Magnetohydrodynamic mixed convection of a viscous dissipating fluid over a vertical plate in porous media with thermal radiation. Math. Comput Modell. 54: 30163036.

[15] Seth GS, Sarkar S, Hussain SM. (2014). Effects of Hall current, radiation and rotation on natural convection heat and mass transfer flow past a moving vertical plate. Ain Shams Eng. J. 5(2): 489-503.

[16] Singh KD, Kumar R. (2010). Effects of chemical reactions on unsteady MHD free convection and mass transfer for flow past a hot vertical porous plate with heat generation/absorption through porous medium. Ind. J. Phys. 84(1): 93-106.

[17] Soundalgekar VM. (1972). Unsteady MHD free convection flow past an infinite vertical flat plate with variable suction. Indian J. Pure Appl. Math. 3: 426-436.

[18] Soundalgekar VM. (1979). Effects of Mass Transfer and free convection on the flow past an impulsively started vertical plate. ASME J. of Appl. Mechanics 46: 757-760.

[19] Soundalgekar VM, Vighnesam NV, Takhar HS. (1979). Hall and Ion - Slip effects in MHD Couette flow with heat transfer. IEEE Trans Plasma Sci. 7: 178-182.

\section{NOMENCLATURE}

$u^{\prime}, v^{\prime} \quad$ Velocity components in $\mathrm{x}, \mathrm{y}$ direction

$\mathrm{T} \quad$ Temperature of the fluid

C Concentration of the fluid

g acceleration due to gravity

$\mathrm{C}_{\mathrm{P}} \quad$ Specific heat at constant pressure

$T_{W}^{\prime} \quad$ Temperature at the wall

$C_{W}^{\prime} \quad$ Concentration at the wall

$T_{\infty}^{\prime} \quad$ Ambient Temperature

$C_{\infty}^{\prime} \quad$ Ambient Concentration

$\mathrm{K}$ Thermal conductivity

D coefficient of mass diffusivity

Gr Grashof Number for Heat Transfer

$\mathrm{Gm}$ Grashof number for mass transfer

Sc Schmidt number

$\mathrm{Sr} \quad$ Soret number

Pr Prandtl numbr
S Heat source parameter

$\mathrm{Nu} \quad$ Nusselt number

Sh Sherwood number

m Hall parameter

Ec Eckert number

$V_{0}^{\prime} \quad$ Constant suction

$\mathrm{B}_{0} \quad$ Magnetic strength

S Sink strength parameter

$\mathrm{K}_{2} \quad$ Chemical Reaction parameter

\section{Greek symbols}

$\beta \quad$ coefficient of volume expansion

$\beta^{\prime} \quad$ coefficient of concentration expansion

$\gamma \quad$ coefficient of viscosity

$\theta \quad$ dimensionless temperature

$\phi \quad$ dimensionless concentration

$\tau \quad$ Skin friction coefficient

\section{APPENDIX}

$$
\begin{aligned}
& A_{1}=M_{1}+\frac{1}{K_{0}} \\
& A_{2}=A_{1}+\frac{i \omega}{4} \\
& A_{3}=\frac{G r+G m D_{2}}{a_{2}^{2}-a_{2}-A_{1}} \\
& A_{4}=\frac{G m\left(1-D_{2}\right)}{a_{6}{ }^{2}-a_{6}-A_{1}} \\
& K_{1}=\left[\frac{K v}{V_{0}^{\prime 2}}-\frac{i \omega}{4}\right] \\
& K_{2}=\frac{K v}{V_{0}^{\prime 2}} \\
& a_{2}=\frac{P r+\sqrt{P r^{2}-\operatorname{PrS}}}{2} \\
& a_{4}=\frac{P r+\sqrt{P r^{2}+(P r)(i w-S)}}{2} \\
& a_{6}=\frac{S c+\sqrt{S c^{2}-4 S c K_{2}}}{2} \\
& a_{8}=\frac{1+\sqrt{1+4 A_{1}}}{2} \\
& a_{10}=\frac{1+\sqrt{1+4 A_{2}}}{2 \operatorname{Pr} a_{2}} \\
& D_{1}=\frac{\operatorname{Pr} a_{2}}{a_{2}^{2}-P r a_{2}-\frac{P r}{4}(i w-s)} \\
& D_{2}=\frac{-S c S r a_{2}^{2}}{a_{2}^{2}-S c a_{2}+S c K_{2}} \\
& D_{3}=\frac{\operatorname{Pra}_{8}^{2}\left(A_{3}+A_{4}\right)^{2}}{4 a_{8}^{2}-2 a_{8} \operatorname{Pr}+\frac{\operatorname{PrS}}{4}} \\
& D_{4}=\frac{P r a_{2}^{2} A_{3}^{2}}{4 a_{2}^{2}-2 a_{2} \operatorname{Pr}+\frac{\operatorname{Pr} S}{4}} \\
& D_{5}=\frac{P r a_{6}^{2} A_{4}^{2}}{4 a_{6}^{2}-2 a_{6} \operatorname{Pr}+\frac{\operatorname{PrS}}{4}} \\
& D_{6}=\frac{2 \operatorname{Pr} a_{8} a_{2} A_{3}\left(A_{3}+A_{4}\right)}{\left(a_{2}+a_{8}\right)^{2}-\left(a_{2}+a_{8}\right) \operatorname{Pr}+\frac{\operatorname{PrS}}{4}} \\
& D_{7}=\frac{2 P r a_{2} a_{6} A_{3} A_{4}}{\left(a_{2}+a_{6}\right)^{2}-\left(a_{2}+a_{6}\right) \operatorname{Pr}+\frac{\operatorname{Pr} S}{4}} \\
& D_{8}=\frac{2 P r a_{8} a_{6} A_{4}\left(A_{3}+A_{4}\right)}{\left(a_{6}+a_{8}\right)^{2}-\left(a_{6}+a_{8}\right) \operatorname{Pr}+\frac{\operatorname{PrS}}{4}} \\
& \mathrm{D}_{9}=\left(\mathrm{D}_{3}+\mathrm{D}_{4}+\mathrm{D}_{5}-\mathrm{D}_{6}+\mathrm{D}_{7}-\mathrm{D}_{8}\right) \\
& D_{10}=\frac{S c a_{6}\left(1-D_{2}\right)}{a_{6}^{2}-a_{6} S c+S c K_{1}}
\end{aligned}
$$




$$
\begin{aligned}
& D_{11}=\frac{S c S r a_{2}^{2} D_{1}}{a_{2}^{2}-a_{2} S c+S c K_{1}} \\
& D_{12}=\frac{S c a_{2}-S c S r a_{4}^{2}\left(1-D_{1}\right)}{a_{4}^{2}-a_{4} S c+S c K_{1}} \\
& \mathrm{D}_{13}=-\mathrm{D}_{10}+\mathrm{D}_{11}-\mathrm{D}_{12} \\
& D_{14}=\frac{G r\left(1-D_{1}\right)+G m D_{12}}{a_{4}^{2}-a_{4}-A_{2}} \\
& D_{15}=\frac{G r D_{1}-G m D_{11}+a_{2} A_{3}-\frac{1}{K_{0}} A_{3}}{a_{2}^{2}-a_{2}-A_{2}} \\
& D_{16}=\frac{G m D_{13}+G m D_{10}}{a_{12}^{2}-a_{12}-A_{2}} \\
& D_{17}=\frac{-a_{8}\left(A_{3}+A_{4}\right)+\frac{1}{K_{0}}\left(A_{3}+A_{4}\right)}{a_{8}^{2}-a_{8}-A_{2}} \\
& \mathrm{D}_{18}=-\frac{a_{6} A_{4}-\frac{1}{K_{0}} A_{4}+G m D_{10}}{a_{6}^{2}-a_{6}-A_{2}} \\
& \mathrm{D}_{19}=\mathrm{D}_{14}+\mathrm{D}_{15}+\mathrm{D}_{16}+\mathrm{D}_{17}+\mathrm{D}_{18} \\
& D_{20}=\frac{-S c S r a_{2}^{2} D_{9}}{a_{2}^{2}-S c a_{2}+S c K_{2}} \\
& D_{21}=\frac{-4 S c S r a_{8}^{2} D_{3}}{4 a_{8}^{2}-2 S c a_{8}+S c K_{2}} \\
& D_{22}=\frac{-4 S c S r a_{2}^{2} D_{4}}{4 a_{2}^{2}-2 S c a_{2}+S c K_{2}} \\
& D_{23}=\frac{-4 S c S r a_{6}^{2} D_{5}}{4 a_{6}^{2}-2 S c a_{6}+S c K_{2}} \\
& D_{24}=\frac{-S c S r\left(a_{2}+a_{8}\right)^{2} D_{6}}{\left(a_{2}+a_{8}\right)^{2}-\operatorname{Sc}\left(a_{2}+a_{8}\right)+S c K_{2}} \\
& D_{25}=\frac{-S c S r\left(a_{2}+a_{6}\right)^{2} D_{7}}{\left(a_{2}+a_{6}\right)^{2}-S c\left(a_{2}+a_{6}\right)+S c K_{2}} \\
& D_{26}=\frac{-S c S r\left(a_{6}+a_{8}\right)^{2} D_{8}}{\left(a_{6}+a_{8}\right)^{2}-S c\left(a_{6}+a_{8}\right)+S c K_{2}} \\
& \mathrm{D}_{27}=-\mathrm{D}_{20}+\mathrm{D}_{21}+\mathrm{D}_{22}+\mathrm{D}_{23}-\mathrm{D}_{24}+\mathrm{D}_{25}-\mathrm{D}_{26} \\
& D_{28}=\frac{G r D_{9}+G m D_{20}}{a_{2}^{2}-a_{2}-A_{1}} \quad D_{29}=\frac{-G m D_{27}}{a_{6}^{2}-a_{6}-A_{1}} \\
& D_{30}=\frac{G r D_{3}+G m D_{21}}{4 a_{8}^{2}-2 a_{8}-A_{1}} \quad D_{31}=\frac{G r D_{4}+G m D_{22}}{4 a_{2}^{2}-2 a_{2}-A_{1}} \\
& D_{32}=\frac{G r D_{5}+G m D_{23}}{4 a_{6}^{2}-2 a_{6}-A_{1}} \\
& D_{33}=\frac{G r D_{6}+G m D_{24}}{\left(a_{2}+a_{8}\right)^{2}-\left(a_{2}+a_{8}\right)-A_{1}} \\
& D_{34}=\frac{G r D_{5}+G m D_{23}}{\left(a_{2}+a_{6}\right)^{2}-\left(a_{2}+a_{6}\right)-A_{1}} \\
& D_{35}=\frac{G r D_{8}+G m D_{26}}{\left(a_{6}+a_{8}\right)^{2}-\left(a_{6}+a_{8}\right)-A_{1}} \\
& \mathrm{D}_{36}=-\left[\mathrm{D}_{28}+\mathrm{D}_{29}-\mathrm{D}_{30}-\mathrm{D}_{31}-\mathrm{D}_{32}+\mathrm{D}_{33}-\mathrm{D}_{34}+\mathrm{D}_{35}\right] \\
& D_{37}=\frac{-2 P r a_{8}\left(A_{3}+A_{4}\right) a_{10} D_{19}}{\left(a_{8}+a_{10}\right)^{2}-\left(a_{8}+a_{10}\right)-\frac{P r}{4}(i w-s)} \\
& D_{38}=\frac{2 \operatorname{Pr} a_{8}\left(A_{3}+A_{4}\right) a_{4} D_{14}}{\left(a_{4}+a_{8}\right)^{2}-\left(a_{4}+a_{8}\right)-\frac{\operatorname{Pr}}{4}(i w-s)} \\
& D_{39}=\frac{2 \operatorname{Pr} a_{8}\left(A_{3}+A_{4}\right) a_{12} D_{15-} 2 \operatorname{Pr} a_{2} a_{8} A_{3} D_{17}+\operatorname{Pr}\left(a_{2}+a_{8}\right) D_{6}}{\left(a_{2}+a_{8}\right)^{2}-\left(a_{2}+a_{8}\right)-\frac{\operatorname{Pr}}{4}(i w-s)} \\
& D_{40}=\frac{2 \operatorname{Pr} a_{8}\left(A_{3}+A_{4}\right) a_{12} D_{16}}{\left(a_{8}+a_{12}\right)^{2}-\left(a_{8}+a_{12}\right)-\frac{\operatorname{Pr}}{4}(i w-s)} \\
& D_{41}=\frac{2 \operatorname{Pr} a_{8}^{2}\left(A_{3}+A_{4}\right) D_{17}-2 \operatorname{Pr} a_{8} D_{3}}{4 a_{8}^{2}-2 a_{8}-\frac{\operatorname{Pr}}{4}(i w-s)} \\
& D_{42}=\frac{2 \operatorname{Pr} a_{8}\left(A_{3}+A_{4}\right) D_{18}-2 P r a_{6} a_{8} A_{4} D_{17}+\operatorname{Pr}\left(a_{6}+a_{8}\right)}{\left(a_{6}+a_{8}\right)^{2}-\left(a_{6}+a_{8}\right)-\frac{P r}{4}(i w-s)}
\end{aligned}
$$

$$
\begin{aligned}
& D_{43}=\frac{2 \operatorname{Pr} a_{8} a_{6}\left(A_{3}+A_{4}\right) D_{17}-2 \operatorname{Pra}_{6} a_{8} D_{16} A_{4}+\operatorname{Pr}\left(a_{6}+a_{8}\right) D_{8}}{\left(a_{6}+a_{8}\right)^{2}-\left(a_{6}+a_{8}\right) \operatorname{Pr}-\frac{\operatorname{Pr}}{4}(i w-s)} \\
& 2 \operatorname{Pr} a_{2} a_{10} A_{3} D_{18} \\
& D_{44}=\frac{2 \operatorname{Pr} a_{2} a_{10} A_{3} D_{18}}{\left(a_{2}+a_{10}\right)^{2}-\left(a_{2}+a_{10}\right) \operatorname{Pr}-\frac{\operatorname{Pr}}{4}(i w-s)} \\
& D_{45}=\frac{2 \operatorname{Pr} a_{2} a_{4} D_{14}}{\left(a_{2}+a_{4}\right)^{2}-\left(a_{2}+a_{4}\right) \operatorname{Pr}-\frac{\operatorname{Pr}}{4}(i w-s)} \\
& D_{46}=\frac{2 \operatorname{Pr} a_{2} a_{6} A_{3} D_{17}+2 P r a_{2} a_{6} D_{15} A_{4}+\operatorname{Pr}\left(a_{2}+a_{6}\right) D_{7}}{\left(a_{2}+a_{6}\right)^{2}-\left(a_{2}+a_{6}\right) \operatorname{Pr}-\frac{\operatorname{Pr}}{4}(i w-s)} \\
& D_{47}=\frac{2 \operatorname{Pr} a_{6} a_{10} A_{4} D_{18}}{\left(a_{6}+a_{10}\right)^{2}-\left(a_{6}+a_{10}\right) \operatorname{Pr}-\frac{\operatorname{Pr}}{4}(i w-s)} \\
& D_{48}=\frac{2 \operatorname{Pr} a_{6} a_{4} A_{4} D_{14}}{\left(a_{4}+a_{6}\right)^{2}-\left(a_{4}+a_{6}\right) \operatorname{Pr}-\frac{\operatorname{Pr}}{4}(i w-s)} \\
& \mathrm{D}_{53}=-\left[\mathrm{D}_{37}+\mathrm{D}_{38}+\mathrm{D}_{39}+\mathrm{D}_{40}+\mathrm{D}_{41}+\mathrm{D}_{42}+\mathrm{D}_{43}+\mathrm{D}_{44}\right. \\
& \left.+\mathrm{D}_{45}+\mathrm{D}_{46}+\mathrm{D}_{47}+\mathrm{D}_{48}+\mathrm{D}_{49}+\mathrm{D}_{50}+\mathrm{D}_{51}+\mathrm{D}_{52}\right] \\
& D_{54}=\frac{S c a_{6} D_{27}}{a_{6}^{2}-S c a_{6}+S c K_{1}} \\
& D_{55}=\frac{S c a_{2} D_{20}-S c S r a_{2}^{2} D_{52}}{a_{2}^{2}-S c a_{2}+S c K_{1}} \\
& D_{56}=\frac{-S c S r a_{4}^{2} D_{53}}{a_{4}^{2}-S c a_{4}+S c K_{1}} \\
& D_{57}=\frac{-2 S c a_{8} D_{21}-4 S c S r a_{8}^{2} D_{41}}{4 a_{8}^{2}-2 S c a_{8}+S c K_{1}} \\
& D_{58}=\frac{-2 S c a_{2} D_{22}-4 S c S r a_{2}^{2} D_{45}}{4 a_{6}^{2}-2 S c a_{6}+S c K_{1}} \\
& D_{59}=\frac{\left.-2 S c a_{6} D_{23}-4 S c S r a_{6}^{2} D_{46}\right]}{4 a_{6}^{2}-2 S c a_{6}+S c K_{1}} \\
& D_{60}=\frac{S c\left(a_{2}+a_{8}\right) D_{24}-\operatorname{ScSr}\left(a_{2}+a_{8}\right)^{2} D_{39}}{\left(a_{2}+a_{8}\right)^{2}-S c\left(a_{2}+a_{8}\right)+S c K_{1}} \\
& D_{61}=\frac{S c\left(a_{2}+a_{6}\right) D_{25}-S c S r\left(a_{2}+a_{6}\right)^{2} D_{48}}{\left(a_{2}+a_{6}\right)^{2}-S c\left(a_{2}+a_{6}\right)+S c K_{1}} \\
& D_{62}=\frac{S c\left(a_{6}+a_{8}\right) D_{26}-S c S r\left(a_{6}+a_{8}\right)^{2} D_{42}}{\left(a_{6}+a_{8}\right)^{2}-\operatorname{Sc}\left(a_{6}+a_{8}\right)+S c K_{1}} \\
& D_{63}=\frac{-S c S r\left(a_{8}+a_{10}\right)^{2} D_{37}}{\left(a_{8}+a_{10}\right)^{2}-S c\left(a_{8}+a_{10}\right)+S c K_{1}} \\
& D_{64}=\frac{-S c S r\left(a_{4}+a_{8}\right)^{2} D_{38}}{\left(a_{4}+a_{8}\right)^{2}-S c\left(a_{4}+a_{8}\right)+S c K_{1}} \\
& D_{65}=\frac{-S c S r\left(a_{8}+a_{12}\right)^{2} D_{40}}{\left(a_{8}+a_{12}\right)^{2}-S c\left(a_{8}+a_{12}\right)+S c K_{1}} \\
& D_{66}=\frac{-S c S r\left(a_{2}+a_{10}\right)^{2} D_{43}}{\left(a_{2}+a_{10}\right)^{2}-S c\left(a_{2}+a_{10}\right)+S c K_{1}} \\
& D_{67}=\frac{-S c S r\left(a_{2}+a_{4}\right)^{2} D_{44}}{\left(a_{2}+a_{4}\right)^{2}-S c\left(a_{2}+a_{4}\right)+S c K_{1}} \\
& D_{68}=\frac{-S c S r\left(a_{2}+a_{12}\right)^{2} D_{47}}{\left(a_{2}+a_{12}\right)^{2}-S c\left(a_{2}+a_{12}\right)+S c K_{1}} \\
& D_{69}=\frac{-S c S r\left(a_{6}+a_{10}\right)^{2} D_{49}}{\left(a_{6}+a_{10}\right)^{2}-S c\left(a_{6}+a_{10}\right)+S c K_{1}} \\
& D_{70}=\frac{-S c S r\left(a_{4}+a_{6}\right)^{2} D_{50}}{\left(a_{4}+a_{6}\right)^{2}-S c\left(a_{4}+a_{6}\right)+S c K_{1}} \\
& D_{71}=\frac{-S c S r\left(a_{6}+a_{12}\right)^{2} D_{51}}{\left(a_{6}+a_{12}\right)^{2}-S c\left(a_{6}+a_{12}\right)+S c K_{1}} \\
& \mathrm{D}_{72}=-\left[\mathrm{D}_{50}+\mathrm{D}_{51}+\mathrm{D}_{52}+\mathrm{D}_{53}+\mathrm{D}_{54}+\mathrm{D}_{55}+\mathrm{D}_{56}+\mathrm{D}_{57}\right. \\
& +D_{58}+D_{59}+D_{60}+D_{61}+D_{62}+D_{63}+D_{64}+D_{65} \\
& \left.+\mathrm{D}_{66}+\mathrm{D}_{67}+\mathrm{D}_{68}+\mathrm{D}_{69}+\mathrm{D}_{70}+\mathrm{D}_{71}\right] \\
& D_{73}=\frac{-G r D_{53}-G m D_{56}}{a_{4}^{2}-a_{4}-A_{2}}
\end{aligned}
$$




$$
\begin{aligned}
D_{74}= & \frac{-G r D_{37}-G m D_{63}}{\left(a_{8}+a_{10}\right)^{2}-\left(a_{8}+a_{10}\right)-A_{2}} \\
D_{75}= & \frac{-G r D_{38}-G m D_{64}}{\left(a_{4}+a_{8}\right)^{2}-\left(a_{4}+a_{8}\right)-A_{2}} \\
D_{76}= & \frac{-G r D_{39}+\frac{1}{K_{0}} D_{33}-\left(a_{2}+a_{8}\right) D_{33}}{\left(a_{2}+a_{8}\right)^{2}-\left(a_{2}+a_{8}\right)-A_{2}} \\
D_{77}= & \frac{-G r D_{40}-G m D_{65}}{\left(a_{8}+a_{12}\right)^{2}-\left(a_{8}+a_{12}\right)-A_{2}} \\
D_{78}= & \frac{-G r D_{41}-G m D_{57}-\frac{1}{K_{0}} D_{30}+2 a_{8} D_{30}}{4 a_{8}^{2}-2 a_{8}-A_{2}} \\
D_{79}= & \frac{-G r D_{42}-G m D_{62}+\frac{1}{K_{0}} D_{35}-\left(a_{6}+a_{8}\right) D_{35}}{\left(a_{6}+a_{8}\right)^{2}-\left(a_{6}+a_{8}\right)-A_{2}} \\
D_{80}= & \frac{-G r D_{43}-G m D_{66}}{\left(a_{2}+a_{10}\right)^{2}-\left(a_{2}+a_{10}\right)-A_{2}} \\
D_{81}= & \frac{-G r D_{44}-G m D_{67}}{\left(a_{2}+a_{4}\right)^{2}-\left(a_{2}+a_{4}\right)-A_{2}} \\
D_{82}= & \frac{-G r D_{45}-G m D_{58}-\frac{1}{K_{0}} D_{31}+2 a_{2} D_{31}}{4 a_{2}^{2}-2 a_{2}-A_{2}} \\
D_{83}= & \frac{-G r D_{46}-G m D_{59}-\frac{1}{K_{0}} D_{32}+2 a_{2} D_{31}}{4 a_{6}^{2}-2 a_{6}-A_{2}} \\
&
\end{aligned}
$$

$$
\begin{aligned}
D_{84}= & \frac{-G r D_{47}-G m D_{68}}{\left(a_{2}+a_{12}\right)^{2}-\left(a_{2}+a_{12}\right)-A_{2}} \\
D_{85}= & \frac{-G r D_{48}-G m D_{61}-\frac{1}{K_{0}} D_{34}+\left(a_{2}+a_{6}\right) D_{34}}{\left(a_{2}+a_{6}\right)^{2}-\left(a_{2}+a_{6}\right)-A_{2}} \\
D_{86}= & \frac{-G r D_{49}-G m D_{69}}{\left(a_{6}+a_{10}\right)^{2}-\left(a_{6}+a_{10}\right)-A_{2}} \\
D_{87}= & \frac{-G r D_{50}-G m D_{70}}{\left(a_{4}+a_{6}\right)^{2}-\left(a_{4}+a_{6}\right)-A_{2}} \\
D_{88}= & \frac{-G r D_{51}-G m D_{71}}{\left(a_{6}+a_{12}\right)^{2}-\left(a_{6}+a_{12}\right)-A_{2}} \\
D_{89}= & \frac{-G r D_{52}-G m D_{55}+\frac{1}{K_{0}} D_{25}-a_{2} D_{28}}{a_{2}^{2}-a_{2}-A_{2}} \\
D_{90}= & \frac{-G m D_{72}}{a_{12}^{2}-a_{12}-A_{2}} \\
& -\frac{-G m D_{54}+\frac{1}{K_{0}} D_{29}-a_{6} D_{29}}{a_{6}^{2}-a_{6}-A_{2}} \\
D_{91}= & \frac{-\frac{1}{K_{0}} D_{36+a_{8} D_{36}}}{a_{8}^{2}-a_{8}-A_{2}} \\
\mathrm{D}_{92} & -\left[\mathrm{D}_{73}+\mathrm{D}_{74}+\mathrm{D}_{75}+\mathrm{D}_{76}+\mathrm{D}_{77}+\mathrm{D}_{78}+\mathrm{D}_{79}+\mathrm{D}_{80}\right. \\
\mathrm{D}_{93}= & +\mathrm{D}_{81}+\mathrm{D}_{82}+\mathrm{D}_{83}+\mathrm{D}_{84}+\mathrm{D}_{85}+\mathrm{D}_{86}+\mathrm{D}_{87}+\mathrm{D}_{88} \\
& \left.+\mathrm{D}_{89}+\mathrm{D}_{90}+\mathrm{D}_{91}+\mathrm{D}_{92}\right]
\end{aligned}
$$

